\title{
İbreli tomrukların traktörle kablo çekimi ile bölmeden çıkarılmasında birim zaman analizi
}

Time and motion analysis on cable skidding with agricultural tractors of coniferous logs

\author{
İsmail ŞAFAK ${ }^{1}$ \\ Mehmet EKER ${ }^{2}$ \\ Mahir ERDEM ${ }^{3}$ \\ İlhami TURAN ${ }^{3}$
}

${ }^{1}$ Ege Ormancılık Araştırma Enstitüsü Müdürlüğü, İzmir

${ }^{2}$ Süleyman Demirel Üniversiteisi, Orman Fakülltesi, Isparta

${ }^{3}$ Batı Karadeniz Ormancılık Araştırma Enstitüsü Müdürlüğ̈̈, Bolu

Sorumlu yazar (Corresponding author) İsmail ȘAFAK

isafak35@hotmail.com

Geliş tarihi (Received)

06.08.2018

Kabul Tarihi (Accepted)

31.10.2018
Atıf (To cite this article): SAFAK, I , EKER, M ERDEM, M, TURAN, İ . (2019). İbreli tomrukların traktörle kablo çekimi ile bölmeden çıkarılmasında birim zaman analizi. Ormancılık Araştırma Dergisi, 6 (1), 47-58.

DOI: https://doi.org/10.17568/ogmoad.451128

\section{$\ddot{O} \mathbf{z}$}

Odun ham maddesi üretimi birim fiyatlarının hassas şekilde hesaplanması, üretim birim zamanlarının doğruluğuna bağlıdır. Günümüzde üretim birim zamanları, iş-zaman etütleriyle elde edilen bazı değişkenlere bağlı olarak türetilmiş katsayıların kullanılmasıyla belirlenmektedir. Bu makale, bölmeden çıkarma tekniklerinden biri olan traktörle kablolu çekim işlerine ait birim zamanların belirlenmesi amacıyla hazırlanmıştır. Araştırmada kızılçam, karaçam, göknar ve sarıçam ağaç türlerinden elde edilen odun ham maddesinin traktöre bağlı kablo ile zeminde çekilerek bölmeden çıkarılması işlemi için çeşitli değişkenler dikkate alınarak iş-zaman analizleri yapılmıştır. Veriler, Adana, Bolu ve Kastamonu Orman Bölge Müdürlüklerinin programlı üretim sahalarından doğrudan zaman ölçme yöntemiyle elde edilmiştir. Araştırma sonucunda, tomrukların kablo çekimi ile bölmeden çıkarılmasında; parça sayısı, kablo uzunluğu, güzergâh eğimi ve yük miktarı değişkenleri dikkate alınarak metreküp başına insan çalışma zamanı ile makine çalışma zamanı ağaç türü bazında ayrı ayrı hesaplanmıștır. Nitekim kablo uzunluğunun 100 metre, güzergâh eğiminin $\% 50$ ve çekilen parça sayısının 5 adet olduğu bir ibreli traktörle kablolu çekim ișleminde metreküp başına insan çalışma zamanı 21,26 dk/100, makine çalışma zamanı 17,60 dk/100 olarak saptanmıştır.

Anahtar Kelimeler: Birim zaman, iş etüdü, zaman analizi, kızılçam, karaçam, sarıçam, göknar

\begin{abstract}
The precise calculation of the unit cost of the timber logs depends on the accuracy of unit working time in harvesting operation. Currently, the unit working time is determined by using derived coefficients depending on some variables obtained through previous time studies. This study was conducted to estimate unit time of cable skidding with agricultural tractor as one of the timber extraction methods. In this research, by taking various variables into account, time study analysis was performed on extraction of wood-raw materials obtained from Turkish red pine, black pine, fir and Scots pine tree species by using a cable attached to the tractor. The data were obtained from the programmed harvesting sites of Adana, Bolu and Kastamonu Forest Regional Directorates by implementing direct time measurement method. As a result of the research, in the extraction of logs from the harvesting units by cable skidding, human working time and machine working time per cubic meter were calculated separately on the basis of tree types by considering the variables including the number of pieces, cable length, slope of the road, and the amount of load. Besides, it was determined that average human and machine working time was respectively 21,26 and $17,60 \mathrm{~min} / 100$ per cubic meter under the conditions of $100 \mathrm{~m}$ skidding distance, 50 percent slope gradient, and 5 pieces at each shift in cable skidding for coniferous logs.
\end{abstract}

Keywords: Standart time, work study, time analysis, Turkish red pine, Black pine, Scots pine, fir 


\section{Giriş}

İş (işin miktarı ve yapılış zamanı) ölçümüyle nitelikli bir işçinin, tanımlanmış bir performans düzeyinde, belirli bir işi başarabilmesi için gerekli olan zaman hesaplanmaktadır (Prokopenko, 2003). İş ölçümünün ana amacı işin yapılış süresini tespit etmektir. İş ölçümü, bir işlemin belirli çalışma şartları altında ve belirli yöntemlerle, yeteri kadar eğitim, bilgi ve yeteneğe sahip bir işçi tarafından, bir iş günü boyunca aşırı yorgunluk yaratmayacak bir çalışma hızı (normal tempo) ile yapılması için geçen sürenin tespit edilmesidir. Ölçümle elde edilen bu süreye, işçinin kişisel ihtiyaçları ve beklenmeyen gecikmeler eklendiğinde bulunan değere birim zaman (standart zaman) denir (Kobu, 1998).

Ormancılıkta birim zaman değerleri, odun ham maddesi üretimi, ağaçlandırma ve fidanlık işleri gibi çeşitli alanlarda, iş gücü maliyetlerinin belirlenmesinde kullanılmaktadir. Ayrica, odun ham maddesi üretimi, damga programlarının hazırlanması, fidanlık faaliyetlerinin oluşturulması, doğa yürüyüşü aktivitelerinin hesaplanması ve Sosyal Güvenlik Kurumu iş bitirme sürelerinin tahmin edilmesi gibi çeşitli alanlarda da birim zaman değerlerinden yararlanılmaktadır.

Odun ham maddesi başta olmak üzere orman ürünleri üretiminde, özellikle iş gücüne dayalı fiili masraflar Orman Genel Müdürlüğünün (OGM) giderleri içinde önemli bir girdi kalemidir. $\mathrm{Bu}$ maliyetlerin yüksekliği, OGM'nin asli ürün (Anonim, 1996) üretimine dayalı işletme sürekliliğini etkilemesi açısından önemli bir tehdit unsurudur. Diğer taraftan üretim maliyetlerindeki bir birimlik artış dahi OGM'nin rekabet kabiliyetini etkilemektedir. $\mathrm{Bu}$ araştırmada konu edilen ve çeşitli yöntemlerle elde edilen birim zaman değerleri, orman asli ürünlerinin üretim maliyetlerini ve dolayısıyla satış fiyatını etkilemesi nedeniyle önemlidir.

Türk ormancılığında, odun ham maddesi üretimi ve diğer ormancılık faaliyetlerine yönelik zaman analizleri 40 y1l öncesine dayanmaktadır. Bunlardan bazılar1, üretim (Geray, 1978; İlter ve ark., 1986; Dingil, 1988; Acar, 1994; Karaman, 1997; Eker, 2004; Göksu, 2010; Önal, 2013); ağaçlandırma (Birler ve ark., 1979; İlter ve ark., 1988; Şirin, 1989; Çok, 2001); sıklık bakımı (İlter, 1989); kültür bakımı (Atasoy, 1992); fidan üretimi (Acar ve İktüeren, 1985; Birler ve Koçar, 1994); tohum meşcereleri (İlter ve ark., 1997); orman depolarında yükleme ve istifleme (Karaman, 1991), dağlık kesimde bazı orman traktörleri ile kısa ve orta mesafeli vinçli hava hatlarının çalışması (Bayoğlu ve ark., 1993); kavak ağaçlandırmalarında budama, kesim ve tomruklama ile kesim sonrası dip kütüklerinin sökülmesi (Zoralioğlu ve ark. 2005) ve ağır tomrukların taşınabilir el vinci ile kamyona yüklenmesi (Acar, 2016) işlerine yönelik olarak gerçekleştirilmiştir.

Öztürk ve Akay (2007), ormancılıkta üretim çalışmalarında tarım traktörlerinden daha etkin yararlanma imkânlarını araştırmışlar, üretim çalışmalarına uygun tarım traktörlerinin özelliklerini, bu çalışmalara özgü ekipman tiplerini ve bunların fonksiyonlarını açıklamışlardır. Öztürk (2009) ise kayın tomruklarının MB Trac 900 sürütücü ile 40140 m'lik sürütme mesafesinde yukarıya doğru bölmeden çıkarılması işleri için birim zaman ölçümü yapmıştır. Eker ve Acar (2014), dikili ağaçların kesilmesi, tomruklanması, kabuklarının soyulması ve bölmeden çıkarılması işlerinde gerçekleştirilen bazı araştırma sonuçlarını özetlemişlerdir. Bölmeden çıkarma ile ilgili bazı çalışmalar Tablo 1'de sunulmuştur.

Üretim sürecinde kullanılan araç ve gereçlerdeki teknolojik değişimler, makineli çalışmadan (teknolojiden) yana tercihlerin artması (bölmeden çıkarma işlerinde hayvan gücü kullanım oranının oldukça azalması, tarım traktörlerinin yaygın şekilde kullanılmaya başlaması gibi) ve iş sağlığı ve

Tablo 1. Bölmeden çıkarma sürecine yönelik bazı çalışmalar (Eker ve Acar, 2014)

Table 1. Summary of some previous studies about logging productivity in Turkey (Eker and Acar, 2014)

\begin{tabular}{|c|c|c|c|c|c|}
\hline Kaynak & Süreç & $\begin{array}{l}\text { Ağaç } \\
\text { Türü }\end{array}$ & $\begin{array}{c}\text { Eğim } \\
(\%)\end{array}$ & $\begin{array}{l}\text { Mesafe } \\
(\mathrm{m})\end{array}$ & Verim \\
\hline Acar (1993) & Traktörle kablo çekim & İbreli & 70 & 69 & $5,27 \mathrm{~m}^{3} / \mathrm{sa}$ \\
\hline \multirow{3}{*}{ Acar (1994) } & MB-Trac 800 kablo çekim & $\begin{array}{r}\text { İbreli } \\
\text { Yapraklı }\end{array}$ & $30-85$ & 50 & $\begin{array}{r}6,8 \mathrm{~m}^{3} / \mathrm{sa} \\
3,76 \mathrm{~m}^{3} / \mathrm{sa}\end{array}$ \\
\hline & MB-Trac 900 kablo çekim & $\begin{array}{r}\text { İbreli } \\
\text { Yapraklı }\end{array}$ & $40-60$ & 50 & $\begin{array}{l}6,49 \mathrm{~m}^{3} / \mathrm{sa} \\
6,16 \mathrm{~m}^{3} / \mathrm{sa}\end{array}$ \\
\hline & Traktörle kablo çekim & $\begin{array}{r}\text { İbreli } \\
\text { Yaprakl1 }\end{array}$ & $32-52$ & 50 & $\begin{array}{l}6,01 \mathrm{~m}^{3} / \mathrm{sa} \\
2,75 \mathrm{~m}^{3} / \mathrm{sa}\end{array}$ \\
\hline Öztürk (2001) & MB-Trac 900 sürütme & İbreli & 10 & $300-500$ & $6,36 \mathrm{~m}^{3} / \mathrm{sa}$ \\
\hline Öztürk (2009) & MB-Trac 900 sürütme & Yaprakl1 & 35 & 105 & $8,7 \mathrm{~m}^{3} / \mathrm{sa}$ \\
\hline
\end{tabular}


güvenliğine yönelik kuralların uygulanması hususundaki gelişmeler, 288 Sayılı Tebliğ'de (1996) yer alan birim zaman analizlerinin yeniden hesaplanmasını gerekli kılmaktadır. Bu makalede, $\mathrm{m}^{3}$ birimi ile ölçülen ve tomruk niteliğindeki odun ham maddesinin traktöre monte edilmiş vinç sistemine bağlı çelik halat (kablo) yardımıyla bölmeden çıkarılması işlemine ait birim zaman değerlerinin tespit edilmesi konu edilmiştir.

\section{Materyal ve Yöntem}

\subsection{Materyal}

Üretim sahalarında gerçekleştirilen bölmeden çıkarma işlerine yönelik birim zaman ölçümleri ile ölçümlerde kullanılan formlar makalenin ana materyalini oluşturmaktadır. Yuvarlak odunların orta çaplarının ölçülmesinde mekanik çap ölçer, ağaç boyları ile gövde uzunluklarının ölçülmesinde ve mesafelerin belirlenmesinde şerit metre, sürütmenin gerçekleştirildiği kablo güzergâhının eğiminin ölçülmesinde klizimetre kullanılmıştır.

İşçi çalışma zamanının tespitinde, üzerinde gözlem ve ölçüm yapılan çalışanların iş güvenliği kurallarına uygun ve kişisel koruyucu donanımla çalıştırılması esas alınmıştır. Ölçümler, çalışanlara ağaç kesme ve boylama operatörü (AKBO) meslek standartları ölçüsünde (Engür, 2014) baret, çelik burunlu ayakkabı, eldiven ve ikaz yeleği gibi donanımlar kullandırılarak gerçekleştirilmiştir.

Koşulları tanımlanmış olan traktöre monteli vinç ile tomrukların bölmeden çıkarılması işinin gerçekleştirilme zaman ve hızının kaydedilmesi ve söz konusu işin önceden saptanmış bir performans düzeyinde yürütülebilmesi için gerekli zamanın hesaplanması amacı ile doğrudan iş ve zaman ölçümü tekniği (Prokopenko, 2003) kullanılmıştır. Doğrudan ölçme çalışmaları kapsamında, çalışma hızının tayin edilip çalışma hızı ile standart çalışma temposu arasında bağlantı kurulması için performans değerlendirme teknikleri de dikkate alınmıştır. Bu kapsamdaki veriler, Hanhard marka kronometre kullanılarak 1/100 dk (desimal) cinsinden ölçülmüş ve kaydedilmiştir.

Ürünlerin traktöre bağlı kablo ile zeminde çekilerek bölmeden çıkarılmasında çekme işlemi aşağıdan yukarıya doğru gerçekleştirilmiştir. Bu kapsamda 135 adet göknar ölçümü Bolu Orman Bölge Müdürlüğünde (OBM), 139 adet sarıçam ölçümü Kastamonu OBM'de, 116 adet karaçam ile 107 adet kızılçam tomruğunun ölçümü ise Adana OBM'de gerçekleştirilmiş olup toplamda 497 adet ölçüm yapılmıştır. Ölçümler belirtilen OBM'lerin olağan üretim sahalarında 9 Şubat 2015'te başla- mış ve 11 Kasım 2016'da tamamlanmıştır. Tablo 2'de çekilen ürünlerin çap ve boylarına yönelik ortalamalar sunulmuştur.

Tablo 2. Ürünlerin ortalama çap ve boylar1 Table 2. Mean diameters and heights of the logs

\begin{tabular}{lcc}
\hline Ağaç türü & $\begin{array}{c}\text { Ürünlerin } \\
\text { çap ort. } \\
(\mathrm{cm})\end{array}$ & $\begin{array}{c}\text { Ürünlerin } \\
\text { boy ort. } \\
(\mathrm{m})\end{array}$ \\
\hline Göknar & 34,40 & 4,69 \\
Sarıçam & 36,19 & 5,32 \\
Karaçam & 21,75 & 2,50 \\
Kızılçam & 22,50 & 2,38 \\
İbreli & 33,17 & 3,33 \\
\hline
\end{tabular}

Ölçümlerin gerçekleştirildiği sahaların arazi engeli bakımından dağılımı Tablo 3'te verilmiştir. Bu kapsamda çalışmayı engelleyecek ya da süreyi uzatacak her türlü arazi yüzeyi engeli aşağıdaki gibi kodlanarak yazılmıştır (Eker, 2014). Buna göre,

1- Yok veya az: Kayalık, taşlık, çukur, çıkıntı, dip kütük vb. engelin olmadığı ya da yürümeyi/çalışmayı etkilemeyecek derecedeki zemin yapısı,

2- Orta: Arazi yüzeyinin tamamen kaplanmad1ğ , ancak çıkıntı ve çukurlukların 1-2 m'yi bulup yürüme ve çalışma zamanını kısmen etkileyebildiği yoğunluktaki zemin yapısı,

3- Çok: Büyük kaya blokları, yar oluşumları ve insan boyunu aşan çukurluk ve çıkıntıların arazinin büyük bölümünü kapladığı, çalışmanın ciddi olarak etkilendiği zemin yapısıdır.

Ölçümlerin gerçekleştirildiği sahaların diri örtü yoğunluğu Tablo 4'te verilmiş olup çalışılan ortamdaki odunsu ve otsu diri örtünün varlığının ve yoğunluğunun gözlemsel olarak değerlendirilmesi yapılmıştır (Eker, 2014). Buna göre,

1- Yok veya az: Boyları $1 \mathrm{~m}$ nin altında ve çalışı-

Tablo 3. Arazi engeli durumu

Table 3. Status of the study areas in terms of rugged landscape

\begin{tabular}{lccc}
\hline \multirow{2}{*}{ Ağaç türü } & \multicolumn{3}{c}{ Arazi engeli (ölçüm adedi) } \\
\cline { 2 - 4 } & Yok veya az & Orta & Çok \\
\hline Göknar & 72 & 59 & 4 \\
Sarıçam & 101 & 38 & - \\
Karaçam & 50 & 66 & - \\
Kızılçam & 85 & 22 & - \\
İbreli & 308 & 185 & 4 \\
\hline
\end{tabular}


lan alanın 1/4'ünden daha azını kaplayan/örten yani, çalışma zamanını etkileyemeyecek derecedeki diri örtü,

2- Orta: Boyları $1 \mathrm{~m}$ den az veya fazla, kalın gövdeli, yayvan, yer örtücü ve/veya alanın yarısını kaplayan çalışma zamanını göreceli olarak uzatacak derecedeki diri örtü,

3- Çok: Boyları 1 metreden fazla olan veya alanın 3/4 ünden fazlasını kaplayan yoğunluktaki diri örtü (iş tekniğinin uygulanmasını engelleyen, işçinin çalışmasını engelleyen, çalışma zamanını belirgin şekilde uzatacak derecededir).

Tablo 4. Diri örtünün yoğunluğu Table 4. Density of brush and shrubs

\begin{tabular}{lccc}
\hline \multirow{2}{*}{ Ağaç türü } & \multicolumn{3}{c}{$\begin{array}{c}\text { Diri örtü yoğunluğu } \\
\text { (ölçüm adedi) }\end{array}$} \\
\cline { 2 - 4 } & Yok veya az & Orta & Çok \\
\hline Göknar & 67 & 54 & 14 \\
Sarıçam & 111 & 28 & - \\
Karaçam & 116 & - & - \\
Kızılçam & 60 & 47 & - \\
İbreli & 354 & 129 & 14 \\
\hline
\end{tabular}

Ölçümlerin gerçekleştirildiği sahaların zemin durumu bakımından dağılımı ise Tablo 5'te verilmiştir. Zeminin durumu, çalışma güçlüğü ya da kolaylığı açısından gözlemsel olarak; i) Kuru (kaygan olmayan, işçinin stabil şekilde durabileceği) zemin, ii) Nemli ve yarı kaygan (derin humus kap11) zemin, iii) Islak ve kaygan (çamurlu-karlı) zemin (ibre, yaprak, ince taneli toprak, vb. den dolayı) şeklinde kaydedilmiştir (Eker, 2014).

Tablo 5. Zemin durumu (ölçüm adedi)

Table 5. Ground condition (numbers of measurement)

\begin{tabular}{|c|c|c|c|}
\hline Ağaç türü & $\begin{array}{c}\text { Kuru } \\
\text { zemin }\end{array}$ & $\begin{array}{c}\text { Nemli } \\
\text { ve yar1 } \\
\text { kaygan } \\
\text { zemin }\end{array}$ & $\begin{array}{c}\text { Islak ve } \\
\text { kaygan } \\
\text { zemin }\end{array}$ \\
\hline Göknar & - & 44 & 91 \\
\hline Sarıçam & 25 & 61 & 53 \\
\hline Karaçam & 116 & - & - \\
\hline K1zılçam & 102 & 5 & - \\
\hline İbreli & 243 & 110 & 144 \\
\hline
\end{tabular}

Ölçümlerde tek tamburlu ve ortalama 67 beygir gücüne (HP; horse power) sahip tarım traktörleri kullanılmıştır. Traktör tamburunda kullanılan çelik halatın kalınlığ $12-14$ mm, uzunluğu ortalama 120 m ve karşılık kullanılan ortalama kablo uzunluğu 53,69 metredir. Ortalama güzergâh eğimi $\% 59,5$ olarak ölçülmüş olup rampa ile traktör arasindaki ortalama mesafe ise 102,10 m dir (Tablo 6).

Tablo 6. Sürütme güzergâhı ile ilgili veriler Table 6. The descriptive data about skidding trails

\begin{tabular}{lccc}
\hline $\begin{array}{l}\text { Ağaç } \\
\text { türü }\end{array}$ & $\begin{array}{c}\text { Rampa ile } \\
\text { traktör } \\
\text { arasındaki } \\
\text { ort. mesafe } \\
(\mathrm{m})\end{array}$ & $\begin{array}{c}\text { Çekilen ort. } \\
\text { kablo } \\
\text { uzunluğu } \\
(\mathrm{m})\end{array}$ & $\begin{array}{c}\text { Ortalama } \\
\text { güzergâh } \\
\text { eğimi } \\
(\%)\end{array}$ \\
\hline Göknar & 48,10 & 57,73 & 66,2 \\
Sarıçam & 224,82 & 51,54 & 67,9 \\
Karaçam & 58,84 & 58,03 & 51,3 \\
Kizılçam & 57,70 & 46,69 & 49,3 \\
İbreli & 102,10 & 53,69 & 59,5 \\
\hline
\end{tabular}

Tablo 7. İşçilerin ortalama yaş ve iş deneyimi Table 7. Average ages and work experience of workers

\begin{tabular}{lcccr}
\hline \multirow{2}{*}{$\begin{array}{l}\text { Ağaç } \\
\text { türü }\end{array}$} & \multicolumn{2}{c}{ Sürücünün } & \multicolumn{2}{c}{ Yardımc1 işçilerin } \\
\cline { 2 - 5 } & $\begin{array}{c}\text { Yaş } \\
(\mathrm{y} 1 \mathrm{l})\end{array}$ & $\begin{array}{c}\text { İş } \\
\text { deneyimi } \\
(\mathrm{y} 1 \mathrm{l})\end{array}$ & $\begin{array}{c}\text { Yaş } \\
(\mathrm{y} 1 \mathrm{l})\end{array}$ & $\begin{array}{c}\text { İş } \\
\text { deneyimi } \\
(\mathrm{y} 1 \mathrm{l})\end{array}$ \\
\hline Göknar & 47,00 & 27,10 & 42,35 & 21,56 \\
Sarıçam & 33,24 & 15,90 & 31,23 & 13,93 \\
Karaçam & 40,11 & 19,39 & 31,55 & 7,17 \\
K1zılçam & 44,18 & 15,86 & 34,57 & 10,98 \\
İbreli & 40,82 & 19,31 & 34,37 & 13,70 \\
\hline
\end{tabular}

Ürünlerin traktöre bağl1 kablo ile zeminde çekilerek bölmeden çıkarılması işlemi, 1 traktör sürücüsü ve ürünleri bağlayan 2 yardımcı olmak üzere toplam 3 işçi ile yapılmıştır. Tablo 7'de işçilerin deneyim ve yaş bilgileri verilmiştir. Buna göre en yaşlı traktör sürücüsü 55 ve en yaşlı yardımcı işçi 58 yaşındadır.

\subsection{Yöntem}

Yuvarlak odunların hacminin hesaplanmasında orta yüzey formülünden (Huber formülünden) yararlanılmıştır (Carus, 2002).

$$
\begin{aligned}
& v=\frac{\pi}{4} d^{2} . l \\
& \text { v: Ürün hacimi }\left(\mathrm{m}^{3}\right) \\
& \text { d: Ürünün orta çapı }(\mathrm{m}), \\
& \text { l: Ürünün boyu (m) }
\end{aligned}
$$

Zaman ölçümleri esnasında, çalışanlara hız konusunda uyarı ve önerilerde bulunulmamıştır. İşin gerektirdiği normal çalışma hızı (tempo) göz önünde bulundurularak çalışanın mevcut performansı (performans katsayısı) belirlenmiştir. Buna göre çalışanların performans katsayısı, \%90 ile 
\%110 arasında değerlendirilmiş ve formlara işlenmiştir. (L) ölçüm esnasında öngörülen performans derecesi, $(\mathrm{t})$ ölçülen tek zaman olmak üzere $\left(\mathrm{t}_{\mathrm{i}}\right)$ gerçek tek zaman aşağıdaki formül ile hesaplanmıştır (Doğan, 2015).

$$
t_{i}=\frac{t . L}{100}
$$

\subsubsection{Regresyon analizi}

Regresyon analizinde değişkenler arasındaki ilişki doğrusal ise doğrusal regresyon, değilse doğrusal olmayan regresyon kullanılmaktadır. Oluşturulan bağımlı değişken denkleminin tek bağımsız değişkene dayanması durumunda basit (iki değişkenli) regresyon modeli, iki veya daha fazla bağımsız değişkene dayanması durumunda ise çoklu (çok değişkenli) regresyon modelinden yararlanılmaktadır (Kalaycı, 2016). Araştırmada kullanılan regresyon modeli -y: bağımlı değişken, $\mathrm{x}_{\mathrm{i}}$ : bağımsız değişken, $\beta_{\mathrm{i}}$ : tahmin edilecek parametreler ve hata terimi olmak üzere- aşağıda verilmiştir.

$$
y=\beta_{0}+\beta_{1} x_{1}+\cdots+\beta_{n} x_{n} \varepsilon
$$

Araştırmada, ana faaliyet zamanlarının saptanmasına yönelik modellerin oluşturulmasında IBM SPSS istatistik programının 24. versiyonunda yer alan çok değişkenli doğrusal regresyon modülünden yararlanılmıştır. Araştırmada kullanılan modellerde, sefer başına ana faaliyet zamanı (dk/100) bağımlı değişken; buna karşılık parça sayısı (adet), ürünleri traktöre çekmek amacıyla kullanılan kablonun uzunluğu (m), güzergâhın eğimi (\%) ve çekilen yük hacmi $\left(\mathrm{m}^{3}\right)$ ise bağımsız değişken olarak tanımlanmıştır.

\subsubsection{Birim zaman}

Ormancılıkta birim çalışma zamanı, birim miktardaki (örneğin 1 yapacak odun) ürünü elde etmek için gereken çalışma süresini ifade etmekte olup insan gücü ile yapılan işlerde işçi çalışma zamanı (İÇZ), makine gücü ile yapılan işlerde ise makine çalışma zamanı (MÇZ) olarak nitelendirilir (Eker ve Acar, 2014).

Ana faaliyet zamanı, planlandığ 1 şekilde ve doğrudan doğruya görevin yerine getirilmesine katkıda bulunan faaliyet zamanı olarak ölçülmüştür. Yan faaliyet zamanı, planlandığ 1 şekilde ancak görevin yerine getirilmesine dolaylı olarak katkıda bulunan faaliyet zamanını temsil etmiştir. Buna göre faaliyet zamanı, ana faaliyet zamanı ile yan faaliyet zamanının toplamından oluşturulmuştur.

$$
\text { Faaliyet zamanı }=\begin{gathered}
\begin{array}{c}
\text { Ana faaliyet zamanı } \\
\text { Yan faaliyet zamanı }
\end{array} \\
+
\end{gathered}
$$

Temel zaman, çalışanın 1 birim miktarı yapması için geçen süre olup faaliyet zamanı ile bekleme (akış gereği ara) zamanının toplamından oluşmuştur. Bekleme zamanı, çok küçük zaman değerinde olduğu için bu araştırmada ana faaliyet zamanı içinde değerlendirilmiş ve ayrıca hesaplanmamıştır. Bu nedenle, bu araştırmada temel zaman, faaliyet zamanına eşit olmaktadır.

$$
\text { Temel zaman }=\begin{gathered}
\text { Faaliyet zamanı } \\
+ \\
\text { Bekleme zamanı }
\end{gathered}
$$

IÇZ; temel zaman, dinlenme, dağılım ve hazırlık zamanlarının toplanmasıyla, MÇZ ise temel zaman, nesnel dağılım zamanı ile hazırlık zamanlarının toplanmasıyla elde edilmiştir. Buna göre, dağılım zamanı, akışları planlandığı gibi gerçekleştirebilmek için ek akış dilimlerine ilişkin öngörülen zamanların toplamı olup temel zamanın yüzdesi olarak ifade edilmiştir. Dağılım zamanı, kişisel ve nesnel dağılım zamanlarının toplamından oluşmuştur. Dinlenme zamanı, çalışanın yaptığ 1 işin sonucunda oluşan dinlenme gereksinimini karşılamak için öngörülen zamanların toplamıdır. Çalışanın zorlanma derecesi ve süresine göre değişen dinlenme zamanı, temel zamanın bir yüzde payı olarak gösterilmiştir. Dinlenme zamanı, Peter Steele ve Partners adlı kuruluşun karşılaştırmalı zorluk ve puan dönüştürme tablolarından yararlanılarak belirlenmiştir. Hazırlık zamanı, çalışan tarafından yapılması gereken hazırlıklar için verilen zaman olarak dikkate alınmıştır (Doğan, 2015).

$$
\begin{aligned}
& \text { İÇZ }= \text { Faaliyet (temel) zamanı } \\
&+ \text { Dinlenme zamanı } \\
& \text { + Dağılım zamanı } \\
&+ \text { Hazırlık zamanı } \\
& \mathrm{MÇZ} \mathrm{=} \mathrm{Faaliyet} \mathrm{(temel)} \mathrm{zamanı} \\
& \\
&+ \text { + Nesnel Dağılım zamanı } \\
& \\
&+ \text { Hazırlık zamanı }
\end{aligned}
$$

\section{Bulgular}

\subsection{Ana faaliyet zamanı}

Traktöre bağlı kablo ile yuvarlak odunların zeminde çekilerek bölmeden çıkarılması işleminde sefer başına ana faaliyet zamanının, sırasıyla, i) sürütme güzergâhından sürütülecek ürüne doğru halatın çekilmesi, ii) halatın ürünün uygun uçlarına bağlanması ve sabitlenmesi, iii) yükün çekme vinci ile 
traktöre doğru sürütülmesi ve yukarı doğru çekme esnasında yükün taş, diri örtü, kök vb. materyal-

lere takılması durumunda, yükün yardımcı işçi tarafından kurtarılması akış dilimlerinden oluştu-

Tablo 8. Sefer başına ana faaliyet zamanına yönelik modeller Table 8 . The models on the main working time per shift

\begin{tabular}{|c|c|c|c|}
\hline \multirow{2}{*}{ Ağaç türü } & \multicolumn{3}{|c|}{ Ana faaliyet zaman $1(\mathrm{dk} / 100)^{*}$} \\
\hline & $\mathrm{R}^{2}$ & Açıklama & Model $^{* *}$ \\
\hline Göknar & 0,9390 & Tüm veriler & $y_{a}=-1,695+0,104 . s+0,018 . e+0,621 . h$ \\
\hline Sarıçam & 0,7850 & Tüm veriler & $y_{a}=0,192+0,082 . s+1,686 . h$ \\
\hline \multirow{2}{*}{ Karaçam } & 0,7170 & $\mathrm{p}<3$ & $y_{a}=-3,237+0,110 . s+0,023 . e+2,883 . h$ \\
\hline & 0,8120 & $\mathrm{p}>2$ & $y_{a}=-3,932+0,149 . s+0,083 . e+3,787 . h$ \\
\hline \multirow{2}{*}{ Kızılçam } & 0,8110 & $\mathrm{p}<5$ & $y_{a}=-2,546+0,107 . s+0,085 . e+2,809 . h$ \\
\hline & 0,8730 & $\mathrm{p}>4$ & $y_{a}=0,804+0,131 . s+0,025 . e+5,239 . h$ \\
\hline İbreli & 0,8300 & $\mathrm{p}<7$ & $y_{a}=-0,944+0,102 . s+0,008 . e+0,6616 . p$ \\
\hline
\end{tabular}

" $y_{a}$ : sefer başına ana faaliyet zamanı (dk/100); p: parça sayısı; s:kablo uzunluğu (m); $e$ : güzergah eğimi (\%); $h$ :çekilen yük hacmi $\left(\mathrm{m}^{3}\right)$

${ }^{* *}$ Tabloda sunulan 7 modelin tamamında bağımsız değişkenler arasındaki korelasyon katsayısı 0,80'den küçük, bağımsız değişkenlerin testi önem değeri 0,05 'den küçük, modellerin testi önem değeri 0,05 'den küçük, modellerin durbin-watson testi değeri ise 1,5-2,5 arasındadır.

Tablo 9. Metreküp $\left(\mathrm{m}^{3}\right)$ başına yan faaliyet zamanı Table 9. Supplementary working time per cubic meters

\begin{tabular}{lcccc}
\hline Ağaç türü & $\begin{array}{c}\text { Birinci ve ikinci akışların } \\
\text { ortalama zaman1 } \\
(\mathrm{dk} / 100)\end{array}$ & $\begin{array}{c}\text { Üçüncü akış diliminin } \\
\text { ortalama zaman1 } \\
(\mathrm{dk} / 100)\end{array}$ & $\begin{array}{c}\text { Sefer başına } \\
\text { ort. yük } \\
\text { hacmi }\left(\mathrm{m}^{3}\right)\end{array}$ & $\begin{array}{c}\text { Yan faaliyet } \\
\text { zaman1 } \\
(\mathrm{dk} / 100)\end{array}$ \\
\hline Göknar & 3,61 & 0,53 & 1,050 & 3,94 \\
Sarıçam & 3,61 & 0,53 & 1,050 & 3,94 \\
Kaçam & 3,61 & 0,53 & 1,050 & 3,94 \\
Kızılçam & 3,61 & 0,53 & 1,050 & 3,94 \\
İbreli & 3,61 & 0,53 & 1,050 & 3,94 \\
\hline
\end{tabular}

Tablo 10. Dinlenme zamanı Table 10. Rest time

\begin{tabular}{|c|c|c|c|c|c|c|}
\hline Zorluklar & Zorluk türleri & Göknar & Sarıçam & Karaçam & Kızılçam & İbreli \\
\hline \multirow{5}{*}{$\begin{array}{l}\text { A. Fiziksel } \\
\text { zorluklar }\end{array}$} & Ortalama güç & 19 & 19 & 19 & 19 & 19 \\
\hline & Duruş & 4 & 4 & 4 & 4 & 4 \\
\hline & Titreşim & 1 & 1 & 1 & 1 & 1 \\
\hline & Kisa devre & 1 & 1 & 1 & 1 & 1 \\
\hline & Kısitlayıc giysi & 10 & 10 & 10 & 10 & 10 \\
\hline \multirow{4}{*}{$\begin{array}{l}\text { B. Ussal } \\
\text { zorluklar }\end{array}$} & Düşünsel yoğunluk & 1 & 1 & 1 & 1 & 1 \\
\hline & Tekdüzelik & 0 & 0 & 0 & 0 & 0 \\
\hline & Göz yorgunluğu & 0 & 0 & 0 & 0 & 0 \\
\hline & Gürültü & 1 & 1 & 1 & 1 & 1 \\
\hline \multirow{6}{*}{$\begin{array}{l}\text { C. Çalışma } \\
\text { koşulları }\end{array}$} & Is1/Nem* & 0 & 0 & 6 & 6 & 3 \\
\hline & Havalandırma & 0 & 0 & 0 & 0 & 0 \\
\hline & Buhar & 0 & 0 & 0 & 0 & 0 \\
\hline & Toz & 1 & 1 & 1 & 1 & 1 \\
\hline & Kir & 1 & 1 & 1 & 1 & 1 \\
\hline & Islaklık & 2 & 2 & 2 & 2 & 2 \\
\hline \multicolumn{2}{|c|}{ Toplam puan } & 41 & 41 & 47 & 47 & 44 \\
\hline \multicolumn{2}{|c|}{ Dinlenme pay1 \%'si } & 19 & 19 & 22 & 22 & 21 \\
\hline
\end{tabular}


ğu belirlenmiştir. Sefer başına ana faaliyet zamanı için ağaç türü bazında elde edilen modeller Tablo 8'de sunulmuştur.

Tablo 8'de yer alan modellerden yararlanılarak elde edilen sefer başına ana faaliyet zaman değerleri, sefer başına taşınan yük miktarına $\left(1,050 \mathrm{~m}^{3}\right)$ bölünerek $\mathrm{m}^{3}$ başına ana faaliyet zamanı elde edilmektedir. Sefer başına ortalama taşınan yük miktarı, göknar, sarıçam, karaçam, kızılçam ve ibrelilerde 1,050 olarak belirlenmiştir.

\subsection{Yan faaliyet zamanı}

Traktöre bağlı kablo ile ürünlerin zeminde çekilerek bölmeden çıkarılması işleminde, yan faaliyet zamanının; i) traktörün rampadan sürütme güzergâhının başlangıcına gelmesi, ii) traktöre çekilmiş olan yükün traktör hareket ettirilerek rampaya sürütülmesi, iii) rampaya getirilen ürünlerin halat uçlarından sökülmesi ve halatının toplanması akış dilimlerinden oluştuğu belirlenmiştir. Tablo 9'da tür bazında $\mathrm{m}^{3}$ başına yan faaliyet zamanı sunulmuştur.

Metreküp başına elde edilen ana faaliyet zamanı ile $\mathrm{m}^{3}$ başına yan faaliyet zamanı toplanarak $\mathrm{m}^{3}$ başına faaliyet zamanı elde edilmektedir. Bu faaliyet zamanının, temel zamana eşit olduğu belirlenmiştir.

\subsection{Dinlenme zamanı}

Dinlenme zamanı pay1, Peter Steele ve Partners adlı kuruluşun karşılaştırmalı zorluk ve puan dönüştürme tablolarından yararlanılarak belirlenmiş ve Tablo 10'da sunulmuştur. Buna göre dinlenme payı, ağaç türü bazında değişiklik göstermekle birlikte, ibreli türler grubu için toplam çalışma zamanının \%21'idir.

\subsection{Dağılım zamanı}

Dağılım zamanı, kişisel ve nesnel dağılım zamanı olarak iki grupta değerlendirilmiştir. Kişisel dağılım zamanı su içme ve tuvalete gitme zamanlarından oluşmaktadır. Nesnel dağılım zamanı ise tomruğun zemine takılmasının giderilme zamanı, traktöre yakıt koyma zamanı, kablonun bağlantısından çıkma zamanı, halat tamir zamanı ile çamura batan traktörün kurtarılma zamanlarının toplamından oluşmaktadır (Tablo 11).

Sigara içme zamanı, iş güvenliği nedeniyle kişisel dağılım zamanı içinde dikkate alınmamıştır. Çalışma amacına uygun olmayan telefon ve/veya arkadaşla görüşme zamanı ile çay içme zamanı dinlenme zamanı kapsamında değerlendirilmiş olup kişisel dağılım zamanı içinde verilmemiştir. Traktörün arızalanmasına (497 ölçüm için yapılan tüm çalışma zamanında) çok seyrek (1 kez 5,65 dk/100) rastlandığ 1 için nesnel dağılım zamanı içinde dikkate alınmamıştır.

\subsection{Hazırlık zamanı}

Traktörün yanaşma yerinin düzenlenmesi için 6 $\mathrm{dk} / 100$, traktörün yer değiştirmesi için $4 \mathrm{dk} / 100$ ve kullanılacak malzemelerin araca yüklenmesi ve indirilmesi $(10 \mathrm{~m})$ zamanı için 1,14 dk/100 olmak üzere günlük hazırlık zamanı 11,14 dk/100 olarak dikkate alınmıştır. Hazırlık zamanının günlük sürütme işlemi yapılan ürün miktarına (20) oranlanmasıyla $\mathrm{m}^{3}$ başına hazırlık zamanı $0,56 \mathrm{dk} / 100$ olarak elde edilmiştir.

\subsection{Birim zaman (İÇZ ve MÇZ)}

Bir $\mathrm{m}^{3}$ ürünün birim zaman1, i) temel zaman $(\mathrm{dk} / 100)$, ii) dinlenme zamanı payı (\%), iii) dağ1lım zamanı payı (\%) ve iv) hazırlık zamanı pay1nın $(\mathrm{dk} / 100)$ toplamından oluşmaktadır. Bu paylar ile ilgili değerler yukarıda sunulmuş olup kablolu çekim için metreküp başına birim zaman sırasıyla yöntem başlığında açıklanan işlemler sonucunda elde edilmektedir.

İÇZ ve MÇZ bir örnekle aşağıda açıklanmıştır.

Sürütme mesafesinin $100 \mathrm{~m}$, eğimin $\% 50$ ve çekilen yük hacminin $1,500 \mathrm{~m}^{3}$ olduğu bir göknar orman alanında ürünlerin araziden kablolu çekim ile çekilmesi durumunda IÇ̧Z ve MÇZ aşağıdaki gibi hesaplanır. Bu değerleri aşağıdaki modelde yerine koyarak sefer başına göknar ana faaliyet zamanı $\left(y_{a}\right)$ elde edilir.

$y_{a}=-1,695+0,104 . s+0,018 . e+0,621 . h$

$y_{a}=-1,695+0,104.100+0,018.50+0,621.1,500$

Matematiksel işlemler yapıldığında sefer başına ana faaliyet zamanı dk/100 olarak hesaplanmaktadır. Buna göre, metreküp başına ana faaliyet zamanı $10,54 / 1,050=10,03 \mathrm{dk} / 100$ bulunur.

Yan faaliyet zamanı Tablo 9'dan 3,94 dk/100; dinlenme zamanı Tablo 10'dan \%19; İÇZ için dağ1lım zamanı Tablo 11'den \%7,83; MÇZ için nesnel dağılım zamanı Tablo 11'den \%6,06; metreküp başına hazırlık zamanı ise $0,56 \mathrm{dk} / 100$ olarak hesaplanarak verilmiştir.

Faaliyet Zamanı $=($ Ana Faaliyet Zaman $1+$ Yan Faaliyet Zamanı) olup

Faaliyet Zamanı $=10,03+3,94=13,97 \mathrm{dk} / 100$ olarak hesaplanır. Bu hesaplanan faaliyet zaman1, bekleme zamanı dikkate alınmadığı için aynı zamanda temel zamana eşittir. Buna göre, bir met- 
reküp ürünün traktörle kablolu çekilmesi için İÇZ aşağıdaki eşitlik yardımıyla hesaplanır.

İÇZ = Temel Zaman + Dinlenme Zamanı + Dağ1lım Zamanı + Hazırlık Zamanı

$\dot{\mathrm{I} C ̧ Z}=13,97+(13,97 \mathrm{x} 0,19)+(13,97 \mathrm{x} 0,0783)+0,56$

İÇZ $=18,28 \mathrm{dk} / 100$ olarak hesaplanmıştır.

Bir metreküp ürünün traktörle kablolu çekilmesi için gereken makine çalışma zamanı (MÇZ) aşağıdaki eşitlik yardımıyla hesaplanır.

MÇZ = Temel Zaman + Nesnel Dağılım Zamanı + Hazırlık Zamanı

$\mathrm{MÇZ}=13,97+(13,97 \times 0,0606)+0,56$

$\mathrm{MÇZ}=15,38 \mathrm{dk} / 100$ olarak hesaplanmıştır.
Yukardaki hesaplamalar dikkate alınarak diğer türler için de benzer şekilde kablolu çekim için metreküp başına İÇZ ve MÇZ zamanı (standart zaman) hesaplanabilir.

Ürünlerin çekilmesinde kullanılan maksimum kablo uzunluğu göknarda $180 \mathrm{~m}$, sarıçamda 110 $\mathrm{m}$, karaçamda $110 \mathrm{~m}$, kızılçamda $85 \mathrm{~m}$ ve ibreli modelde 180 m'dir. Metreküplü ürünleri traktöre bağlı kablo ile zeminde çekerek bölmeden çıkarma işleminde sürütme mesafesinin yukarıda belirtilen kablo uzunluklarından daha çok olması durumunda, birinci yol olarak aradaki fark için yeni ara istasyon(lar) kurularak ürünler bölmeden çıkarılabilir. Bu kapsamda varsayılan ara istasyon sayısında kullanılan kablo uzunluklarına göre model kurularak elde edilen değerler toplandığında

Tablo 11. Dağılım zamanı

Table 11. Distribution time

\begin{tabular}{|c|c|c|c|c|}
\hline \multicolumn{2}{|c|}{ Dağılım zamanı bileşenleri } & \multirow{2}{*}{$\begin{array}{c}\text { Siklik } \\
5\end{array}$} & \multirow{2}{*}{$\begin{array}{c}\text { Ort. zaman } \\
(\mathrm{dk} / 100)\end{array}$} & \multirow{2}{*}{$\begin{array}{c}\begin{array}{c}\text { Toplam } \\
\text { zaman } \\
(\mathrm{dk} / 100)\end{array} \\
2,5\end{array}$} \\
\hline Kişisel dağılım & Su içme zamanı & & & \\
\hline zaman1 & Tuvalet ihtiyacı zamanı & 3 & 2,0 & 6,0 \\
\hline \multicolumn{4}{|c|}{ Kişisel dağ 1 lım zamanının günlük çalışma zamanı (480 dk) içindeki \% payı } & 1,77 \\
\hline \multirow{5}{*}{$\begin{array}{l}\text { Nesnel dağ } 11 \text { ım } \\
\text { zamanı }\end{array}$} & Tomruğun zemine takılmasının giderilme zamanı & 3 & 2,7 & 8,1 \\
\hline & Traktöre yakıt koyma zamanı & 1 & 5,0 & 5,0 \\
\hline & Kablonun bağlantısından çıkma zamanı & 3 & 2 & 6,0 \\
\hline & Halat tamir zaman1 & 1 & 5 & 5,0 \\
\hline & Traktör batması & 1 & 5 & 5,0 \\
\hline \multicolumn{3}{|c|}{ Nesnel dağılım zamanının günlük çalışma zamanı (480 dk) içindeki \% payı } & & $\% 6,06$ \\
\hline \multicolumn{3}{|c|}{ Toplam dağılım zamanının günlük çalışma zamanı (480 dk) içindeki \% payı } & & $\% 7,83$ \\
\hline
\end{tabular}

Tablo 12. Bir (m) sürütme mesafesi için metreküp $\left(\mathrm{m}^{3}\right)$ başına İÇZ ve $\mathrm{MÇZ}$

Table 12. Machine and human working time per cubic meter for one $(\mathrm{m})$ distance

\begin{tabular}{|c|c|c|c|c|}
\hline \multirow[t]{2}{*}{ Ağaç türü } & \multicolumn{2}{|c|}{$\begin{array}{c}\text { Rampaya } 1 \mathrm{~m} \text { boş geliş ve yüklü dönüş için } \mathrm{m}^{3} \\
\text { başına ortalama fark zamanı }(\mathrm{dk} / 100)^{*}\end{array}$} & \multicolumn{2}{|c|}{$\begin{array}{l}1 \mathrm{~m} \text { kablo çekimi için } \mathrm{m}^{3} \text { başına } \\
\text { ortalama fark zaman }(\mathrm{dk} / 100)^{*}\end{array}$} \\
\hline & İÇZ & MÇZ & İÇZ & MÇZ \\
\hline Göknar & 0,0306 & 0,0256 & 0,0853 & 0,0713 \\
\hline Sarıçam & 0,0429 & 0,0359 & 0,1089 & 0,0910 \\
\hline Karaçam & 0,0850 & 0,0694 & 0,1616 & 0,1320 \\
\hline Kızılçam & 0,0893 & 0,0729 & 0,1776 & 0,1451 \\
\hline İbreli & 0,0496 & 0,0408 & 0,1315 & 0,1082 \\
\hline
\end{tabular}

*: Zaman değerlerine dağılım ve dinlenme payı eklenmiş, yan faaliyet ve hazırlık payı ise tekrar oluşturulması için eklenmemiştir.

sürütme mesafesi elde edilebilir. İkinci yol olarak, uzun sürütme mesafelerinde, modellerde kullanılan kablo uzunluğundan sonraki fark sürütme mesafesi için Tablo 12'deki değerlerden yararlanılabilir. Buna göre, traktörün rampadan $1 \mathrm{~m}$ boş geliş ve yüklü dönüşüne karşılık olarak $\mathrm{m}^{3}$ başına elde edilen IÇZ ve MÇZ ile $1 \mathrm{~m}$ kablo çekimi için $\mathrm{m}^{3}$ başına elde edilen IÇZ ve MÇZ değeri, fark sürütme mesafesi ile çarpılarak sürütme mesafesi için fark zaman değeri elde edilir. Bu fark zaman değeri, işlem sonucu ile toplanarak toplam kablo ile çekim zamanı bulunabilir.

\section{Tartışma ve Sonuç}

288 Sayılı Tebliğ’de (1996), kesme-boylama, böl- 
meden çıkarma, yükleme ve taşıma işlemleri için birim zamanlar, yapraklı ve ibreli türler için genel olarak dikkate alınmaktadır. $\mathrm{Bu}$ araştırmada ise birim zamanlar, hem tür ve ibreli bazında hesaplanmış hem de yan faaliyet, dinlenme, dağılım ve hazırlık zaman payları incelenebilir bir şekilde eklenmiştir.

OGM maliyetleri içinde, odun üretiminde çalışanlara ödenen iş gücü ve üretim maliyetleri önemli bir girdi kalemidir. Odun üretiminde çalışanlara yönelik gerçekleştirilen iş gücü ödemelerinin esasını, her bir işlemin gerçekleştirilmesi için çalışanların harcadığı birim zamanlar oluşturmaktadır. Bu nedenle, birim zamanların uygun biçimde tespit edilmesi, hem kaynağın yöneticisi olan OGM'nin stratejilerini oluşturması hem de çalışanların geliri açısından özel önem taşımaktadır. Aynı kapsamda, araştırma verileri, özel sektör tarafından rekabete yönelik odun üretim maliyetlerinin tespit edilmesinde kullanıldığı için de önemlidir.

Akış dilimi bazında gerçekleştirilen zaman ölçümleri, işlem bazında birim zamanın temelini oluşturan ana faaliyet, yan faaliyet ve ek faaliyet ile kişisel ve nesnel dağılım zamanlarının tespit edilmesini sağlamaktadır. Bu durum, ergonomi, etkinlik veya etken olmayan zamanların saptanmasına yönelik araştırmalarda, işlemin yapılmasında harcanan zamanı akış dilimleri bazında ortaya koyduğu için sapmaların hangi akış diliminden kaynaklandığını ortaya çıkarmaktadır.
Traktörlerin çekim gücü, kablo mesafesi uzadıkça azalmaktadır. Kablo ile bölmeden çıkarma işleminde, mevcut traktörlerin yaklaşık $1 \mathrm{~m}^{3}$ ürünü (3-5 parça hâlinde) etkin olarak çekebilmesi için maksimum kablo uzunluğunun 120 m'yi geçmemesi uygun olacaktır. Bu nedenle, çekim yapılması gereken kablo uzunluğunun, traktörün etkin olarak çekebileceği kablo uzunluğundan fazla olmas1 durumunda bulgular başlığında sunulan birinci yöntemde belirtilen ara istasyonların kullanılması uygun olacaktır.

Araştırmada elde edilen sonuçlar, 288 Sayılı Tebliğ'de (1996) yer alan zaman değerleri ve araştırma kapsamına giren bazı literatür sonuçları ile karşılaştırılmıştır. Tebliğde \% cinsinden 0-30; 31-60; $61-100$ ve 100 'den büyük olmak üzere dört eğim grubu için sürütme mesafesi 1500 m'ye kadar olan sahalarda yukarıdan aşağıya hayvan ve insan çalışma zamanları en az iki çalışan ile hesaplanmıştır. $\mathrm{Bu}$ araştırmada ise birim zaman hesaplamasında 3 çalışandan yararlanılmış ve elde edilen modelde eğim, sürütme mesafesi, traktöre bağlanan parça sayısı ve yük hacmi dikkate alınmıştır. Araştırmada ürünleri çekmede kullanılan maksimum kablo uzunluğu göknarda $180 \mathrm{~m}$, sarıçamda $110 \mathrm{~m}$, karaçamda $110 \mathrm{~m}$, kızılçamda $85 \mathrm{~m}$ ve ibreli modelde 180 metredir. Buna göre, metreküplü ürünleri traktöre bağlı kablo ile zeminde çekilerek bölmeden ç1karma işleminde, sürütme mesafesinin 110 metreden daha uzun olması durumunda aradaki fark için yeni ara istasyon(lar) kurularak ürünler bölmeden

Tablo 13. Araștırmada elde edilen insan çalıșma zamanlarının Anonim (1996) zamanları ile karșılaştırılması Table 13. Comparison of the study results on human working time with Anon. (1996)

\begin{tabular}{|c|c|c|c|c|c|c|c|c|}
\hline $\begin{array}{c}\text { Kablo } \\
\text { uzun. (m) }\end{array}$ & $\begin{array}{c}\text { Güz. } \\
\text { eğimi (\%) }\end{array}$ & $\begin{array}{r}\text { Göknar } \\
\text { (dk/100) }\end{array}$ & $\begin{array}{l}\text { Sarıçam } \\
(\mathrm{dk} / 100)\end{array}$ & $\begin{array}{c}\text { Karaçam } \\
(\mathrm{dk} / 100)\end{array}$ & $\begin{array}{l}\text { Kizılçam } \\
\text { (dk/100) }\end{array}$ & $\begin{array}{c}\text { Araştırma } \\
(\mathrm{dk} / 100)\end{array}$ & $\begin{array}{c}\text { İbreli } \\
\text { Tebliğ } \\
(\mathrm{dk} / 60)\end{array}$ & Fark $(\%)^{*}$ \\
\hline 50 & 25 & 11,12 & 12,88 & 17,51 & 22,34 & 14,76 & 25,50 & 42,13 \\
\hline 100 & 25 & 17,40 & 17,83 & 26,72 & 30,44 & 21,01 & 51,00 & 58,80 \\
\hline 200 & 25 & 34,80 & 35,65 & 53,43 & 60,89 & 42,02 & 102,00 & 58,80 \\
\hline 500 & 25 & 87,00 & 89,14 & 133,58 & 152,22 & 105,06 & 264,00 & 60,21 \\
\hline 50 & 50 & 11,66 & 12,88 & 20,07 & 23,12 & 15,00 & 33,00 & 54,54 \\
\hline 100 & 50 & 17,94 & 17,83 & 29,28 & 31,22 & 21,26 & 66,00 & 67,79 \\
\hline 200 & 50 & 35,88 & 35,65 & 58,56 & 62,43 & 42,51 & 132,00 & 67,79 \\
\hline 500 & 50 & 89,71 & 89,14 & 146,40 & 156,08 & 106,28 & 330,00 & 67,79 \\
\hline 50 & 75 & 12,20 & 12,88 & 22,64 & 23,89 & 15,25 & 37,50 & 59,34 \\
\hline 100 & 75 & 18,48 & 17,83 & 31,85 & 31,99 & 21,50 & 75,00 & 71,33 \\
\hline 200 & 75 & 36,97 & 35,65 & 63,69 & 63,98 & 43,00 & 150,00 & 71,33 \\
\hline 500 & 75 & 92,42 & 89,14 & 159,23 & 159,94 & 107,51 & 375,00 & 71,33 \\
\hline 50 & 105 & 12,86 & 12,88 & 25,71 & 24,82 & 15,54 & 54,00 & 71,22 \\
\hline 100 & 105 & 19,14 & 17,83 & 34,92 & 32,92 & 21,80 & 108,00 & 79,82 \\
\hline 200 & 105 & 38,27 & 35,65 & 69,85 & 65,83 & 43,59 & 216,00 & 79,82 \\
\hline 500 & 105 & 95,68 & 89,14 & 174,62 & 164,58 & 108,98 & 540,00 & 79,82 \\
\hline
\end{tabular}


çıkarılabilir. Bu kapsamda varsayılan ara istasyon sayısında kullanılan kablo uzunluklarına göre hesaplanan İÇZ ve MÇZ değerleri toplandığında toplam sürütme zamanı elde edilebilir.

Araştırmada diri örtü, arazi engeli, zemin durumu gibi parametrelerin çalışma koşullarına olan etkisi saptanmak istenmiş olsa da, araştırma süresinin kısıtlı olması nedeniyle ölçüm sayılarının düşük tutulması ve ölçümlerde seçilen arazi özelliklerinin bu etkileri saptamaya yönelik olmaması nedeniyle diğer parametrelere yönelik anlamlı sonuç üretilememiştir.

Önal (2013), kızılçam için ortalama 61m kablo uzunluğu için traktörle çekme zamanını $\mathrm{m}^{3}$ başına IÇZ ve MÇZ için 5,30 dk saptamıştır. Bu araştırmada ise \%50 eğimde aynı mesafe için $\mathrm{m}^{3}$ başına İÇZ 24,90 dk/100, MÇZ ise 20,44 dk/100 olarak bulunmuştur. Önal'ın (2003) sonuçlarının düşük olması, sadece çekme zamanının dikkate alınmasından, rampaya taşıma, dağılım ve dinlenme pay-

Tablo 14. Araştırmada elde edilen makine çalışma zamanlarının Anonim (1996) zamanları ile karşılaştırılması Table 14. Comparison of the study results on machine working time with Anon. (1996)

\begin{tabular}{|c|c|c|c|c|c|c|c|c|}
\hline \multirow[b]{2}{*}{$\begin{array}{c}\text { Kablo } \\
\text { uzun. (m) }\end{array}$} & \multirow{2}{*}{$\begin{array}{c}\text { Güz. } \\
\text { eğimi } \\
(\%)\end{array}$} & \multirow[b]{2}{*}{$\begin{array}{l}\text { Göknar } \\
(\mathrm{dk} / 100)\end{array}$} & \multirow[b]{2}{*}{$\begin{array}{l}\text { Sarıçam } \\
(\mathrm{dk} / 100)\end{array}$} & \multirow[b]{2}{*}{$\begin{array}{l}\text { Karaçam } \\
(\mathrm{dk} / 100)\end{array}$} & \multirow[b]{2}{*}{$\begin{array}{l}\text { K1zılçam } \\
(\mathrm{dk} / 100)\end{array}$} & \multicolumn{3}{|c|}{ İbreli } \\
\hline & & & & & & $\begin{array}{c}\text { Araştırma } \\
(\mathrm{dk} / 100)\end{array}$ & $\begin{array}{c}\text { Tebliğ } \\
(\mathrm{dk} / 60)\end{array}$ & $\begin{array}{l}\text { Fark } \\
(\%)^{*}\end{array}$ \\
\hline 50 & 25 & 9,39 & 10,86 & 14,40 & 18,35 & 12,25 & 21,00 & 41,67 \\
\hline 100 & 25 & 14,64 & 15,00 & 21,93 & 24,97 & 17,40 & 42,00 & 58,57 \\
\hline 200 & 25 & 29,28 & 30,00 & 43,86 & 49,94 & 34,80 & 80,00 & 56,50 \\
\hline 500 & 25 & 73,20 & 75,00 & 109,64 & 124,85 & 86,99 & 212,00 & 58,97 \\
\hline 50 & 50 & 9,85 & 10,86 & 16,50 & 18,99 & 12,45 & 28,00 & 55,53 \\
\hline 100 & 50 & 15,10 & 15,00 & 24,02 & 25,60 & 17,60 & 56,00 & 68,57 \\
\hline 200 & 50 & 30,19 & 30,00 & 48,05 & 51,20 & 35,20 & 112,00 & 68,57 \\
\hline 500 & 50 & 75,48 & 75,00 & 120,12 & 128,01 & 88,01 & 298,00 & 70,47 \\
\hline 50 & 75 & 10,30 & 10,86 & 18,59 & 19,62 & 12,65 & 35,00 & 63,85 \\
\hline 100 & 75 & 15,55 & 15,00 & 26,12 & 26,23 & 17,80 & 70,00 & 74,57 \\
\hline 200 & 75 & 31,10 & 30,00 & 52,24 & 52,47 & 35,61 & 138,00 & 74,20 \\
\hline 500 & 75 & 77,75 & 75,00 & 130,59 & 131,17 & 89,02 & 354,00 & 74,85 \\
\hline 50 & 105 & 10,85 & 10,86 & 21,11 & 20,38 & 12,90 & 45,00 & 71,34 \\
\hline 100 & 105 & 16,10 & 15,00 & 28,63 & 26,99 & 18,05 & 90,00 & 79,95 \\
\hline 200 & 105 & 32,19 & 30,00 & 57,27 & 53,99 & 36,09 & 180,00 & 79,95 \\
\hline 500 & 105 & 80,48 & 75,00 & 143,16 & 134,97 & 90,23 & 450,00 & 79,95 \\
\hline
\end{tabular}

larının dikkate alınmamasından veya düşük tutulmasından kaynaklanabilir.

Tablo 13 ve Tablo 14'te eğimler $\% 25, \% 50, \% 75$ ve $\% 105$; parça sayısı ibrelilerde 5 adet ve bir seferde çekilen yük hacmi ise ibrelilerde $1,050 \mathrm{~m}^{3}$ olmak üzere çeşitli sürütme mesafeleri için hesaplanan bölmeden çıkarma zamanları ile Tebliğ zamanları (Anonim, 1996) karşılaştırılmıştır. Buna göre İÇZ zamanlarında, ibreli türlerde en az \%42,13 oranında Tebliğ değerleri daha yüksektir. Tebliğde yer alan hayvan çalışma zamanları, ibreli türlerde traktör çalışma zamanından en az \% 41,67 yüksek hesaplanmıştır.

\section{Teșekkür}

Bu makalede Orman Genel Müdürlüğü, Batı Karadeniz, Doğu Akdeniz ve Marmara Ormancılık Araştırma Enstitüsü Müdürlüklerince 2015-2017 yıllarında yürütülen "Göknar, Sarıçam, Karaçam ve Kızılçamın Üretim İşlerinde Birim Zaman Analizi" konularındaki iki araştırma projesinin verilerinden yararlanılmıştır.

\section{Kaynaklar}

Acar, H., H. 1994. Ormanc1likta Transport Planları ve Dağlık Arazide Orman Transport Planının Oluşturulması, KTU Fen Bilimleri Enstitüsü Doktora Tezi, 150s

Acar, H., H. 2016. Tomrukların kamyona yüklenmesi çalışmalarında taşınabilir el vinci ve polietilen oluk kombinasyonu sistemi. İstanbul Üniversitesi Orman Fakültesi Dergisi, C:66, s.329-339

Acar, İ., İktüeren, Ş. 1985. Torbalı Orman Fidanlığında Kızılçam Fidan Üretimine İlişkin İş-Zaman Analizleri. Ormancılık Araştırma Enstitüsü, Teknik Bülten No:69, 37s

Anonim, 1996. Orman Genel Müdürlüğü, Asli Orman Ürünlerinin Üretim İşlerine Ait 288 Sayılı Tebliğ. Ankara 
Atasoy, H. 1992. Doğu Karadeniz Bölgesinde El Araçlarıyla Kültür Bakımı Standart Zamanları. Ormancılık Araştırma Enstitüsü, Teknik Bülten No:235, 70s

Bayoğlu, S., Acar, H., H., Şentürk, N. 1993. Dağlık arazide bölmeden çıkarma araçlarında maliyet analizi ve minimum çalışma süresinin araştırılması. İ.Ü. Orman Fakültesi Dergisi, Seri: B, Cilt:43, Sayı:1-2, s.45-56

Birler, AS., Doğru, M., Usta, HZ. 1979. Ağaçlandırma Çalışmalarına Ait Birim Zaman Cetvelleri. Kavak ve Hızlı Gelişen Orman Ağaçları Araştırma Müdürlüğü, Y1llık Bülten No:15, s.1-48

Birler, A. S., Koçar, S. 1994. Kavak Fidanlıkları İçin Maliyet Analizleri. Kavak ve Hızlı Gelişen Orman Ağaçları Araştırma Müdürlügüu, Teknik Bülten No:161, 29s

Carus, S. 2002. Bazı hacim formüllerinin seksiyon, gövde ve bağıl uzunluklara göre kıyaslanması. Süleyman Demirel Üniversitesi Orman Fakültesi Dergisi Seri: A, Cilt: 1, s.101-114

Çok, N. 2001. Elazı ̆ İli Gözeli Mikro Havzasında Ağaçlandırma İşlerine İlişkin İş Analizleri ve Standart Zamanlar. Kahramanmaraş Sütçü İmam Üniversitesi Fen Bilimleri Enstitüsü Yüksek Lisans Tezi, 104s

Dingil, S. 1988. Çeşitli Boylarda Sedir Yapacak Yuvarlak Odunların Çeşitli Alan Koşullarında Sürütmesinin Fiyat Analizleri. Ormancılık Araştırma Enstitüsü, Teknik Bülten No:204, 36s

Doğan, A. 2015. İş Etüdü Yöntem Bilgisi. TC Bilim, Sanayi ve Teknoloji Bakanlığı Verimlilik Genel Müdürlü$\breve{g u ̈}$, Ders Notu, Ankara, 216s

Eker, M. 2004. Ormanc1likta Odun Hammaddesi Üretiminde Y1llık Operasyonel Planlama Modelinin Geliştirilmesi, KTU Fen Bilimleri Enstitüsü Doktora Tezi, 230s

Eker, M. 2014. Süreçler-İşlem Adımları-İș Tanımları-Ö1çüm Formları, Yayınlanmamış Bilgi Notu, Isparta, 43s

Eker, M., Acar, H., H. 2014. Kesim ve bölmeden çıkarma işlerinde birim çalışma zamanlarının irdelenmesi. II. Ulusal Akdeniz Orman ve Çevre Sempozyumu. 22-24 Ekim 2014, Isparta, Bildiriler Kitab1, s.260-268

Engür, M., O. 2014. Odun Üretiminde Çalışanların Eğitimi Ağaç Kesme ve Boylama Operatörü, Orman Genel Müdürlüğü. Ankara, 393s

Geray, A., U. 1978. Ormancılıkta Gerçek Tarife Bedeli ve Bunun İşletmenin Entansitesini Tayin Hususunda Bir Kriter Olarak Kullanılması Üzerine Araştırmalar. İÜ Yayın No: 2409, Orman Fakültesi Yayın No: 255, 158s, İstanbul

Göksu, E., 2010. Devlet Orman İşletmelerinde Odun Hammaddesi Üretiminin PERT Tekniği İle Planlanması (Ardıç Orman İşletme Şefliği Örneği). Bartın Üniversitesi Fen Bilimleri Enstitüsü Yüksek Lisans Tezi, 117s

İlter E., Öktem, E., Türegün, H., Yüksel, S. 1997.
Orman Ağacı Tohum Tedarikinde Standart Zamanların Belirlenmesi. Ormancılık Araştırma Enstitüsü, Teknik Bülten No:267, 37s

İlter E., Türegün, H., Yüksel, S., Savyer, S., Şirin, G., Cevik, İ., Acar, İ., Dinç, B. 1988. Fidanlıklarda Fidan Üretim Maliyetlerinin Saptanması Üzerine Araştırmalar. Ormancılık Araştırma Enstitüsü, Teknik Bülten No:198, 47s

İlter, E. 1989. Tabii ve Suni Olarak Yetiştirilmiş ve Sıklık Çağındaki Kızılçam (Pinus brutia Ten.) ve Karaçam (Pinus nigra Arnold) Meșcerelerinde Yapılacak S1klık Bakım İşlemlerine ait İş-Zaman Analizleri. Ormancılık Araştırma Enstitüsü, Teknik Bülten No:207, 64s

İlter, E., Çakır, M., Yüksel, S. 1986. Büyükdüz Araştırma Ormanı Serisinde Yapacak ve Yakacak Odun Üretiminden Satışına Değin Gerekli Tüm Süreçlere İlişkin İş Analizlerinin ve Bunlara Dayalı Birim Maliyetlerin Saptanması. Ormancılık Araştırma Enstitüsü, Teknik Bülten No:158, 72s

Kalaycı, Ş. 2016. SPSS Uygulamalı Çok Değișkenli İstatistik Teknikleri. Kalkan Matbaacılık San. Tic. ve Ltd. Şti., 7. Bask1, 426s

Karaman, A. 1991. Orman Depolarında Liebher 902 ile Tomruk Yükleme ve İstiflemenin Zaman Verim ve Masraf Yönünden Karşılaştırılması. KTU Fen Bilimleri Enstitüsü, Yüksek Lisans Tezi. 97s, Trabzon

Karaman, A. 1997. Doğu Karadeniz Yöresinde Farklı Çalışma Koşullarında Kesim ve Sürütme İşlerinde İşgüçlüğü Kriterlerinin Araştırılması ve Verim Üzerine Etkisinin Belirlenmesi. KTU Fen Bilimleri Enstitüsü, Doktora Tezi. 221s, Trabzon

Kobu, B. 1998. Üretim Yönetimi, İ.Ü. İşletme Fakültesi, İşletme İktisadı Enstitüsü Araştırma ve Yardım Vakfı Yayın No:04, Onuncu Bask1, İstanbul, 618s

Önal, Y., E. 2013. Odun Hammaddesi Üretim Operasyonlarında Kullanılan Teknolojinin Enerji Tüketimi, Emisyon ve Gürültü Etkilerinin İncelenmesi. SDÜ Fen Bilimleri Enstitüsü, Yüksek Lisans Tezi. 171s

Öztürk, T. 2009. Kayın tomruğunun bölmeden çıkarı1masında Mb Trac 900 sürütücünün verimlilik analizi. İ.Ü. Orman Fakültesi Dergisi, Cilt:59, s.45-59

Öztürk, T. Akay, A., E. 2007. Tarım traktörlerinin orman ürünlerinin üretiminde kullanılmak üzere modifiye edilmesi. 150th Anniversary of Forestry Education in Turkey, Bottlenecks, Solutions, and Priorities in the Context of Functions of Forest Resources 17-19 October 2007. s.1111-1120

Prokopenko, J. 2003, Verimlilik Yönetimi Uygulamalı Elkitabı, Milli Prodüktivite Merkezi Yayın No:476, Ankara, $315 \mathrm{~s}$

Şirin, G. 1989. Doğu Karadeniz Yöresindeki 
Ağaçlandırma İşlerine İlişkin İş Analizleri ve Standart Zamanlar. Ormancılık Araştırma Enstitüsü, Teknik Bülten No:209, 43s

Zoralioğlu, T. Uludağ, S., Koçer, S., Diner, A., Kılıçaslan, H., Karabulut, S. 2005. Kavak Ağaçlandırmaların- da Budama, Kesim ve Kesim Sonrası Dip Kütüklerinin Sökülmesine Yönelik Teknikler ile İşlem Birim Zaman ve Maliyetlerinin Belirlenmesi. Kavak ve Hızlı Gelişen Orman Ağaçları Araștırma Müdürlüğü, Teknik Bülten No:199, 28s 